\section{P-023 NATIONAL TRENDS OF THE INPATIENT DIAGNOSIS, TREATMENT, AND OUTCOMES OF CEREBRAL ANEURYSMS IN LAST DECADE}

D McCarthy*, E Luther, S Chen, S Sur, M Brunet, D Sheinberg, E Peterson, R Starke. University of Miami, Miami, FL

\subsection{6/neurintsurg-2019-SNIS.59}

Introduction Following publication of the ISUIA and ISAT studies, the paradigm for treatment of cerebral aneurysms shifted from open surgical clipping to endovascular embolization as primary therapy in a majority of cases. While this trend has been widely acknowledged, patient population, outcome data and large-scale treatment patterns have not been reported in recent years.

Methods The National Inpatient Sample from 2004-2014 was reviewed. Subarachnoid hemorrhage (SAH) and unruptured aneurysm (UA) discharges were identified along with treatment given, surgical clipping or endovascular repair. UA that were not primary diagnoses were labeled as incidental. The Elixhauser comorbidity readmission index (ELIX) was used to estimate patient baseline health status. SAH severity and outcomes were analyzed with the NIS-SAH severity score (NIS-SSS) and NIS-severity outcome measure (NIS-SOM), which correlate directly with Hunt-Hess score and mRS outcome, respectively. Time trend series plots were created. Following Shapiro-Wilks normality confirmation, linear and logistic regression were utilized to estimate significant changes in the yearly mean or median of treatments. Per capita values were analyzed to control for population growth. Comparisons of means/distributions of normally continuous variables was carried out using least squared means analysis; while, nonparametric distributions were compared with the Wilcoxon rank sum test. P-values of $\leq 0.05$ were considered statistically significant. Statistical analysis performed with SAS 9.4 (Cary, NC).

Results A total of 379,437 SAH and 378,242 UA discharges were reviewed. For UA and SAH, endovascularly treated patients were significantly older $(\mathrm{p}<0.0001)$. SAH patients managed endovascularly were more sick than clipped patients (ELIX 10.4 vs $8.9 ; \mathrm{p}<0.0001$ ); whereas, UA- endovascular patients were healthier than UA-clipped patients (ELIX 2.4 vs $3.9 ; \mathrm{p}<0.0001)$. SAH patients with $\mathrm{NIH}-\mathrm{SSS}>7$, correlating with Hunt-Hess $\geq 4$, were more likely to be managed endovascularly $(\mathrm{p}<0.0001)$. Overall SAH-clipped patients had lower inpatient mortality (11.7 vs. $12.9 ; \mathrm{p}=0.012)$, but a high NIHSOM rate $(54 \%$ vs $50 \% ; \mathrm{p}=0.0002)$. The rate of incidentally inpatient diagnosed UA has significantly risen every year (+1987 yearly; 2004, 10435 vs. 2014, 28795; p<0.0001).

For SAH treatment, yearly discharges for clipping decreased $(-264.1, p=0.0002)$ and increased for endovascular $(+366$, $\mathrm{p}=0.0003)$ treatment (2004 vs. 2014; SAH-clipping 6579 vs 3400; SAH-endovascular 3878 vs 7535). For treated UA, yearly discharges for clipping remained stable and increased for endovascular therapy $(+630, p<0.0001)$ (2004 vs. 2014; UA-clipping 3553 vs 3745; UA-endovascular 3948 vs 9705). These trends remained significant when analyzed by per capita values. Overtime, inpatient mortality decreased for both clipped $(p=0.0494)$ and endovascularly $(p<0.0001)$ treated SAH (2004 vs. 2014; SAH-clipped 13\% vs 11.7\%; SAH-endovascular $15.8 \%$ vs. $12.7 \%$ ). Mortality rates for clipped UA decreased over time $(p=0.0027)$ and did not change for endovascular treated UA (2004 vs. 2014 mortality rates; UA-clipped $1.57 \%$ vs $0.40 \%$; UA-endovascular $0.59 \%$ vs. $0.52 \%$ ). There was no change in NIH-SOM rates over time.
Conclusion Patients with ruptured and unruptured aneurysms are increasingly treated with endovascular therapy over clipping. Mortality rates of ruptured aneurysms is improving regardless of treatment; whereas, mortality in unruptured aneurysms is only improving for surgical clipping.

Disclosures D. McCarthy: None. E. Luther: None. S. Chen: None. S. Sur: None. M. Brunet: None. D. Sheinberg: None. E. Peterson: None. R. Starke: None.

\section{P-024 TARGET ULTRA REGISTRY FOR THE TREATMENT OF SMALL INTRACRANIAL ANEURYSMS, PRELIMINARY RESULTS}

${ }^{1} \mathrm{G}$ Jindal ${ }^{*},{ }^{1} \mathrm{R}$ Almardawi, ${ }^{2} \mathrm{R}$ Gupta, ${ }^{3} \mathrm{G}$ Colby, ${ }^{4} \mathrm{C}$ Schirmer, ${ }^{5} \mathrm{~B}$ Pukenas, ${ }^{6} \mathrm{~S}$ Satti, ${ }^{1} \mathrm{~T}$ Miller, ${ }^{1} \mathrm{D}$ Gandhi. 'University of Maryland, BALTMORE, MD; ${ }^{2}$ Wellstar Health System, Marietta, MD; ${ }^{3}$ Neurosurgery, UCLA Medical Center, Los Angeles, CA; ${ }^{4}$ Geisinger Medical Center, Danville, PA; ${ }^{5}$ Hospital of The University of Pennsylvania, Philadelphia, PA; ${ }^{6}$ Christiana Care Health System, Newark, DE

10.1136/neurintsurg-2019-SNIS.60

Purpose The ULTRA Registry is an ongoing multicenter, national, prospective study designed to assess aneurysm occlusion rates and safety profile of the Target Ultra coil and the Target ${ }^{\circledast 2}$ Nano coil (Stryker Neurovascular, Freemont, CA, USA) in the treatment of small intracranial aneurysms.

Materials and methods The ULTRA registry is a prospective database of patients with small $(<5 \mathrm{~mm})$ intracranial aneurysms treated with Target ${ }^{\circledast}$ Ultra and Target ${ }^{\circledast}$ Nano coils. The primary endpoint is target aneurysm re-intervention or target aneurysm rupture during the follow up period, and secondary endpoints include residual aneurysm and device related or procedural adverse events.

Results Patients were enrolled from December 2013 to January 2019. A total of 100 patients with 100 aneurysms were included, including 49 ruptured aneurysms. The mean age was $56 \pm 11.6$ years, and $75 \%$ were female. Mean aneurysm volume was $17.7 \pm 12.4 \mathrm{~mm}^{3}$ with mean maximum and minimum aneurysm diameters of $3.7 \pm 0.9 \mathrm{~mm}$ and $2.6 \pm 0.7 \mathrm{~mm}$, respectively. Mean packing density was $33.9 \% \pm 16.6 \%$. Stent and balloon assistance was used in 21 and 19 cases, respectively. No flow diverters were used. Initial complete occlusion, minimal residual, and residual aneurysm were reported in 45, 52, and 3 cases, respectively. There were no coil related adverse events and no intraoperative aneurysm ruptures. There were 6 procedural related adverse events: 3 ischemic strokes, 1 cerebral hemorrhage from wire perforation, 1 groin hematoma, and 1 groin infection. There was one procedural related death in the patient with cerebral hemorrhage complication. First follow up using MR angiography at a mean of 5.8 \pm 2.3 months demonstrated complete occlusion, minimal residual, and residual aneurysm in 64\% (42/66), 27\% (18/66), and 9\% $(6 / 66)$ of cases. Second follow up using digital subtraction angiography at a mean of $15.8 \pm 5.4$ months demonstrated complete occlusion, minimal residual and residual aneurysm in $62 \%(26 / 42), 26 \%(11 / 42)$, and $12 \%(5 / 42)$ of cases. To date, there have been 6 aneurysm retreatments $(9 \% ; 6 / 66)$.

Conclusion Initial results of the ULTRA Registry demonstrate adequate efficacy and safety profiles.

Disclosures G. Jindal: 1; C; Stryker Neurovascular, Microvention. 2; C; Penumbra. R. Almardawi: None. R. Gupta: 1; C; Stryker Neurovascular, Rapid Medical. 2; C; Stryker Neurovascular, Ceronovous, Rapid Medical. 6; C; CEC committee MIND trial, Penumbra. G. Colby: 2; C; Medtronic, Stryker, 
Abstract P-024 Table 1 Aneurysm Occlusion Rates

\begin{tabular}{|c|c|c|c|}
\hline Rate of Occlusion & Procedure $(n=100)$ & 3-9 Months $(n=66)$ & 9-18 Months $(n=42)$ \\
\hline $\begin{array}{l}\text { Grade 0: complete } \& \text { total } \\
\text { aneurysm occlusion }\end{array}$ & 33 & 40 & 24 \\
\hline $\begin{array}{l}\text { Grade } 1: \geq 90 \% \text { volumetric } \\
\text { aneurysm occlusion }\end{array}$ & 47 & 13 & 8 \\
\hline $\begin{array}{l}\text { Grade } 2: 70-89 \% \text { volumetric } \\
\text { aneurysm occlusion }\end{array}$ & 15 & 9 & 7 \\
\hline $\begin{array}{l}\text { Grade } 3: 50-69 \% \text { volumetric } \\
\text { aneurysm occlusion }\end{array}$ & 3 & 3 & 2 \\
\hline $\begin{array}{l}\text { Grade } 4: 25-49 \% \text { volumetric } \\
\text { aneurysm occlusion }\end{array}$ & 0 & 1 & 1 \\
\hline $\begin{array}{l}\text { Grade } 5:<25 \% \text { volumetric } \\
\text { aneurysm occlusion }\end{array}$ & 2 & 0 & 0 \\
\hline \multicolumn{4}{|l|}{ Raymond ooclusion Scale } \\
\hline Complete & 45 & 42 & 26 \\
\hline Minimal Residual & 52 & 18 & 11 \\
\hline Residual Aneurysm & 3 & 6 & 5 \\
\hline
\end{tabular}

Microvention. C. Schirmer: 1; C; NIH/NINDS. 6; C; AANS Honoraria, Ownership- NTI. B. Pukenas: 1; C; Stryker Neurovascular. S. Satti: 2; C; Stryker Neurovascular, Penumbra, Cerenovus, Terumo. 6; C; Medtronic - Proctor. T. Miller: None. D. Gandhi: 1; C; Stryker Neurovascular.

\section{P-025 OUTCOME STUDY OF PIPELINE EMBOLISATION DEVICE WITH SHIELD TECHNOLOGY IN UNRUPTURED ANEURYSMS}

${ }^{1} \mathrm{~N}$ Kandasamy*, ${ }^{1} \mathrm{~T}$ Booth, 'J Hart, ${ }^{2} \mathrm{D}$ Atasoy, ${ }^{3} \mathrm{Y}$ Shih-hung. 'Neuroradiology, King's College hospital, London, UK; ${ }^{2}$ Neuroradiology, Karadeniz Technical University Farabi Hospital, Turkey; ${ }^{3}$ Neuroradiology, Taipei Medical University-Municipal Wan Fang Hospital, Taiwan

\subsection{6/neurintsurg-2019-SNIS.61}

Background Pipeline Flex Embolization Device with Shield Technology (Pipeline Shield) has recently been introduced as the third generation of Pipeline flow-diverter devices (FDDs) with a new stent surface modification giving reduced thrombogenicity.

Objective We aimed to evaluate clinical (safety) and radiographic (efficacy) outcomes of the Pipeline Shield.

Methods The 30 day and 1-year mortality and morbidity rates, and the 6 and 18 month radiographic aneurysm occlusion outcomes for procedures performed between March 2016 and January 2018, were reviewed. 3D-TOF-MRA was used for follow up.

Results A total of 44 attempted Pipeline Shield procedures were performed for 41 patients with 44 target aneurysms (total 52 aneurysms treated). $88.5 \%$ were inserted in the anterior circulation and $11.5 \%$ the posterior circulation. $49 / 52$ (94.2\%) aneurysms were saccular, 1/52 (1.9\%) was fusiform. One $(1.9 \%)$ aneurysm was an iatrogenic pseudoaneurysm and one (1.9\%) was a dissecting aneurysm. 71\% (35/49) of the saccular aneurysms were wide-necked (neck >4 mm), 34.6\% $(18 / 52)$ were large $(\geq 10 \mathrm{~mm})$ and $3.8 \%(2 / 52)$ were giant $(\geq 25 \mathrm{~mm})$. The mean aneurysm sac maximal diameter was
$9.2 \mathrm{~mm}$, and mean neck width was $5.1 \mathrm{~mm}$. The cumulative mortality and morbidity rates were $2.3 \%$ and $9.2 \%$ at 1 year, respectively. The adequate occlusion rate was $78.8 \%$ at 6 months and $90.3 \%$ at 18 months.

Conclusions In this pragmatic and independent study, the occlusion rates and safety outcomes were similar to those seen in previously published studies with FDDs and earlier generation PEDs.

Disclosures N. Kandasamy: 6; C; contribution towards institutional study budget. T. Booth: 6; C; institutional study budget support. J. Hart: 6; C; Institutional study budget support. D. Atasoy: None. Y. Shih-hung: None.

\section{P-026 THE USE OF HIGH-FREQUENCY OPTICAL COHERENCE TOMOGRAPHY FOR FOLLOW-UP IMAGING OF TREATED ANEURYSMS}

R King*, M Marsofoi, E Langan, M Shazeeb, G Ughi, C Raskett, A Puri, M Gounis. Radiology, University of Massachusetts, Worcester, MA

\subsection{6/neurintsurg-2019-SNIS.62}

Introduction The use of flow diverters has emerged as an effective treatment of aneurysm. One of the major limitations of flow diverters is the need to put patients on dual anti-platelet therapy (DAPT). The exposure of bare metal struts leads to platelet activation. A method to assess the degree of neointimal tissue ingrowth over the surface of the device could permit patient-specific tailoring of DAPT. Currently, the standard of follow-up for flow diverter patients is digital subtraction angiography (DSA); however, it has been previously reported DSA appearance of complete aneurysm occlusion is not always reliable with continued aneurysm growth. ${ }^{1}$ There have been reported cases of very delayed complications after DAPT has been stopped, ${ }^{2}$ although rare, such complications can be catastrophic.

High Frequency Optical Coherence Tomography (HF-OCT) is a novel intravascular imaging technique designed for use in 